\title{
Distinctive Features and the Liquids in Picard
}

\author{
Ryan Hendrickson \\ Indiana University
}

\section{Introduction}

The class of liquid consonants, which traditionally groups laterals and (most) rhotics (Catford 1977:237), has been called into question by recent research examining phonological features. The primary issue with defining the class based on a shared feature [liquid] is that unlike [nasal], for example, there is no agreed upon measurable phonetic correlate to the phonological feature. Dickey (1997:150) defines [liquid] based on a shared behavior, proposing that the class is comprised of "non-nasal sonorant consonants", a definition that she ultimately rejects. While she argues that they do constitute a natural phonological class based on the shared behavior and distribution of the two types of consonants in numerous languages, Colantoni \& Steele (2005) provide evidence that there are just as many differences as similarities between them in Spanish and French.

The current research examines these consonants in Picard, a Gallo-Romance variety spoken in Northern France and Southern Belgium. The language, which has undergone substantial loss especially over the $20^{\text {th }}$ century, is seeing some revitalization efforts through both written (journals, literature, comic books, etc.) and spoken (social groups, presentations of written works) media. The current research focuses primarily on the Picard spoken in the Vimeu region, which is located northwest of the city of Amiens. The liquids in Picard are interesting both due to their phonotactics as well as the various processes in which they are involved. Firstly, due to their high sonority, these consonants play a larger role as the interior member of a complex consonant cluster (i.e. the consonant closest to the nucleus) than other consonants. Secondly, there are cases of epenthesis and deletion due to some of these phonotactics restrictions. Importantly, some of these restrictions serve to show the similarities between the two types of consonants while others present different behaviors. Finally there is also a process of metathesis, which further serves to distinguish these consonants as it only acts on the rhotic.

This paper is organized as follows. Section 2 outlines previous research on the definition of phonological classes. Section 3 looks at liquid-glide onsets in Picard and proposes that the asymmetric behavior of $/ 1 /$ and $/ \mathrm{r} /$ is due to a difference in place specification. Section 4 examines Picard coda clusters involving liquids and the interaction between sonority and place features. Section 5 presents the conclusions of the current work as well as areas for future research.

\section{Defining a Consonant Class}

Kenstowicz (1994) describes natural classes as groupings of sounds that tend to pattern together in a given language. This very general and basic definition does not say anything about the different ways in which groups of sounds may be similar. Mielke $(2005,2008)$ distinguishes three types of segment classes in phonology, each of which has different criteria for membership. The phonetically natural class is "a group of sounds in an inventory that share one or more phonetic properties, to the exclusion of all other sounds in the inventory" (2008: 12). A phonologically natural class ${ }^{1}$ is "a group of sounds in an inventory that share one or more distinctive features ${ }^{2}$ within a particular feature theory, to the exclusion of all other sounds in the inventory" (2008: 12). Finally, a phonologically active class is "a group of sounds in an inventory that do at least one of the following to the exclusion of other sounds in the inventory" (2008: 12):

\footnotetext{
* I would like to thank the participants at Phonology 2013 and Mid-Phon 2013 for their helpful comments. I would also like to thank Julie Auger and Stuart Davis for their reviews of previous iterations of this work. Finally, I thank the Department of Global Languages and Cultures at Northern Arizona University for helping to fund and make presentation of this work possible.

${ }_{1}^{1}$ For clarity, I use phonologically natural class where Mielke uses natural class.

${ }^{2}$ My emphasis

c 2014 Ryan Hendrickson

Proceedings of Phonology 2013

Completed December 20, 2013
} 
- Undergo a phonological process

- Trigger a phonological process

- Crucially referred to by a static distributional restriction (Mielke, 2008: 12-13)

While phonological analyses have depended on only phonologically active classes in order to explain processes, such arguments become stronger when they also fit into natural classes (both phonetic and phonological). Given the paucity of research that supports classifying the liquid and rhotic consonants as phonetically natural (see Proctor 2011 and McDougall \& Jones 2011 for some research supporting this classification), it does not seem prudent to make this claim.

Furthermore, the distinctive feature [liquid] has been at best weakly defined by previous research. While positive definitions of [liquid] tend to make reference only to which consonants fit into this category, negative definitions such as in Dickey (1997:151) of "non-nasal sonorant consonants" do not define the class in terms of a shared distinctive feature that is absent from all other segments in the inventory. Therefore the current research focuses on whether defining the lateral and rhotic consonants in terms of a phonologically active class is warranted by the distribution of these consonants as well as the processes that they undergo in Picard.

As far as defining the feature(s) common to these consonants, I ultimately adopt a minimalist approach based on the theory of Modified Contrastive Specification (Paradis \& Prunet 1991) as well as The Successive Division Algorithm (Dresher 2009:25-26), which work together to minimally specify segments at the phonological level and state that each segment in a class should only be differentiated by one feature. This leads to the proposal that the lateral and rhotic consonants in Picard have the least amount of specification for consonants and that only the place feature [coronal] distinguishes them at this level.

\section{Liquid-Glide Onsets in Picard}

The phonotactics of Picard allow for complex onsets to surface faithfully if two conditions are met. Firstly, the consonants must not share a place of articulation. This accounts for the lack of [tl] onsets, for example. Secondly, the two consonants increase in sonority and are not adjacent on the sonority scale (i.e. there is an increase of two). Clements (1990) proposes a widely used sonority scale for consonants as seen in (1).

(1) Sonority Scale

Stops $<$ Fricatives $<$ Nasals $<$ Liquids $<$ Glides

While much research refers to Clements' scale, Côté (2000) proposes a scale that divides the liquid consonants so that $/ 1 /$ is less sonorant than $/ \mathrm{r} /$. This follows Jesperson's (1904) original scale. Both scales are considered in the current work as differences or similarities in sonority may play an important role in the distribution of the liquid consonants.

Examples of faithful onset clusters in Picard are presented in (2). Examples (2a-2d) exhibit a sonority difference of at least 3 while example (2e) exhibits a difference of either 2 or 3 depending on the sonority scale adopted, and example (2f) exhibits the smallest sonority difference of only 2.

(2) Onset Clusters in Picard

a. Quand oz étoème piots [e.twem.pjo] (Picardiries)

'When you were children'

b. o n' travaille point [on.tra.vaj] (Picardiries)

'we don't work'

c. il ont décidé d' foaire passer [de.si.ded.fwer] (Picardiries)

'They decided to place (a highway)'

d. Se Fieu [fjø] 'to trust' (Vasseur: 1998)

e. Eine? couleur vraimint [ku.lœr.vre.me] (Picardiries)

'a color really...'

f. moaisons d' presse. Vlo, eine boéne lirie [vlo] (Picardiries)

'publishing houses. There, a good read' 
While onsets must adhere to the conditions of sonority and place differences in order to surface faithfully in Picard, there are consonant sequences in the INPUT that do not meet these criteria (3). Example (3a) shows that the first consonant of the cluster can undergo resyllabification with a preceding vowel. Example (3b) shows the possibility of an epenthetic vowel to allow for resyllabification if the onset cluster follows a consonant. Example (3c) shows the same $/ \mathrm{km} /$ cluster surfacing faithfully phrase-initially. Auger (2001) proposes that the first consonant in the cluster is licensed indirectly by the Intonational Phrase. In summary, initial clusters that violate the restrictions described above only require either epenthesis or indirect licensing to surface and are less telling for the current analysis.

\section{(3) Problematic Onset Clusters}

a. o vo cmincher aveuc quique cose [o.vok.mẽ. Se] (Picardiries) 'we'll start with something...'

b. j'ai vnu pour écmincher no smaine [pur.ek.mẽ.fe] (Picardiries) 'I came to begin our week'

c. Cmint voleu vous qu'i fuch'té mi ? [kmẼ] (Clonneries) 'How do you want them to be me?'

Liquid-Glide onsets in Picard exhibit the same behaviors of resyllabification and epenthesis as the $/ \mathrm{km} /$ clusters in (3). In (4), liquid-glide clusters involving the glide $/ \mathrm{j} /$ show resyllabification (4a-4b) and epenthesis (4c-4d). Examples with the glide $/ \mathrm{w} /$ show similar surface distributions, with one notable exception to be discussed later.

(4) Liquid-Glide Onsets
a. éj n'ai pu rien dit [pyr.jẽ.di] (Lettes: 164) 'I couldn't say anything else'

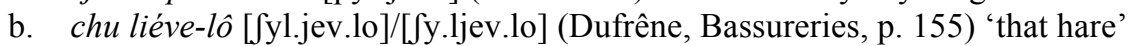
c. i n' gaingne érien [gen.er.jē] (Lettes: 184) 'he wins nothing'
d. aveuc eune mémouère dé liève [del.jev] (Ch'coin 10) 'with a hare's memory'

Examples (3b, 4c, and 4d) show that epenthesis is triggered in these examples by the problematic onset clusters when they follow a consonant. The relevant constraints are proposed in (5) and the analysis for this is shown in tableau (1).

(5) Constraints: Liquid-Glide Onset Epenthesis

WD-CONT: No word-internal epenthesis or deletion

ONS-SON-2: Onset consonants have a minimum sonority distance of at least 2

MAX-C: Input consonants have Output correspondents

$\operatorname{DEP}(\mathrm{e})$ : Output segments [e] have correspondents in the Input

Tableau (1): gaigne érien

\begin{tabular}{|c|c|c|c|c|}
\hline 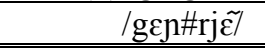 & WD-CONT & ONS-SON-2 & MAX-C & $\operatorname{DEP}(\mathrm{e})$ \\
\hline [ge.ner.je] & & & & $*$ \\
\hline b. $\quad$ [gen.rjẽ & & $* !$ & & \\
\hline [gej.je] & & & $* !$ & \\
\hline d. [gen.re] & $* !$ & & $*$ & \\
\hline e. [gen.re.jé] & $* !$ & & & $*$ \\
\hline
\end{tabular}

In tableau (1), candidate (b) violates ONS-SON-2 by having onset consonants of adjacent sonority. Candidate (c) violates the MAX-C constraint by deleting the word-initial consonant, candidate (d) violates both the MAX-C and the WD-CONT constraints by deleting a word-initial consonant. Candidate (e) fatally violates the WD-CONT constraint due to the word-internal epenthetic [e]. Therefore, candidate (a) is optimal because it only violates the lower-ranked $\operatorname{DEP}(\mathrm{e})$ constraint due to the word-external epenthetic [e]. Given the current constraints, we would expect /lj/ onset clusters to behave similarly, given the possibility that $/ 1 /$ is less sonorous than $/ \mathrm{r} /$. However, as we see in (6), this is not the case as we optionally observe deletion of the word-initial lateral, a process not observed with the rhotic.

(6) Word-Initial Lateral Deletion 
is racache'te chés ieuves ${ }^{3}\left[\int \mathrm{e} . \mathrm{j} ø \mathrm{v}\right]$ (I nn'est qu'd'és croére!, CD) 'they lure the hares'

While it is clear from tableau (1) that sonority does play a role in epenthesis, example (6a) suggests that there is more to the story. If the lateral is in fact specified for [coronal] while the rhotic is not, deletion of the lateral is predicted by a constraint that prohibits onset clusters sharing the same place feature [coronal], while deletion of the rhotic is not. Tableau (2) presents lateral deletion in a lateral-glide onset while new relevant constraints are presented in (7).

(7) Constraints: Lateral Onset Deletion

OCP-ONS [CORONAL]: Onset consonants must not share the place feature [coronal]

*1.G: Avoid syllable contact between a lateral and a glide (rising sonority +2 )

Tableau (2): chés ieuves

\begin{tabular}{|c|c|c|c|c|c|}
\hline$/ \mathbf{e}$ \#ljøv/ & $\begin{array}{c}\text { OCP-ONS } \\
\text { [CORONAL] }\end{array}$ & WD-CONT & ONS-SON-2 & $* 1 . G$ & MAX-C \\
\hline a. [Je.jøv] & & & & & $*$ \\
\hline b. [Sel.jøv] & & & & $* !$ & \\
\hline c. [Je.le.jøv] & & $* !$ & & & \\
\hline d. [ [e.løv] & & $* !$ & & & * \\
\hline e. [je.ljøv] & $* !$ & & $(*)$ & & \\
\hline
\end{tabular}

Candidate (a) wins by only violating the MAX-C constraint. Candidates (c) and (d) violate the WD-CONT constraint, as was seen in tableau (1). Candidates (b) violates the *1.G constraint, which penalizes rising sonority across syllable boundaries where a greater sonority distance constitutes a more serious violation. Crucially, this constraint is ranked with the ONS-SON-2 constraint in order to variably allow for resyllabification as seen in tableau (1). Given that (a) violates a constraint ranked lower than any of the constraints violated by candidates (b-e), the candidate that deletes the $/ 1 /$ is optimal. The constraint ranking from tableaux (1) and (2) is seen in (8).

(8) LG Onset Constraint Ranking

OCP-ONS [CORONAL] $>>$ WD-CONT $>>$ ONS-SON-2, *1.G $>>$ MAX-C $>>$ DEP(e), *r.G

The low-ranking of *r.G allows for the resyllabification of $/ \mathrm{rG} /$ clusters across a syllable boundary while the more highly ranked *1.G constraint allows for deletion. Again, the crucial constraint is the OCPONS [CORONAL] constraint, which ultimately serves to distinguish the rhotic and lateral consonants. Another piece of evidence that supports the highly ranked constraint against shared [coronal] features in onset clusters is the words tchién 'dog' and tchiène 'bitch', which almost categorical exhibits epenthesis when preceded by a consonant (9a-9b). A more stringent constraint against deleting obstruent consonants can account for the absence of deletion of the segment [t $f$ ], thus showing an effect of place without the effect of sonority distance.

(9) Epenthesis from OCP-ONS [CORONAL]

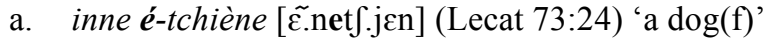

b. deuxième é-tchièn [metf.jen] (Lecat 73:24)'second $\operatorname{dog}(\mathrm{m})$ '

The ranking of constraints in this section has provided additional support for the difference in [coronal] specification for the lateral and rhotic consonants beyond the phonotactics described at the beginning of this section. The presence of this feature for the lateral at the phonological level causes candidates with the lateral to violate the OCP-ONS [CORONAL] constraint when followed by another coronal segment, and as a result, a candidate that deletes the lateral is more optimal than the fully faithful candidate. In section 4, word-final complex consonant clusters are examined, again showing a complex interaction between sonority and the place feature of these consonants.

\footnotetext{
${ }^{3}$ Recall that the word for 'hare' has a word-initial lateral in example (4d). This supports a similar Input for example (6a), thus motivating the claim for deletion.
} 


\section{Complex final clusters in Picard}

The subjunctive mood in Picard is morphologically marked with the morpheme $/ \mathrm{J} /$, which in combination with a consonant-final verb stem, can create some of these more complex and marked structures. Hendrickson \& Auger (2011) show that the distribution of this morpheme is generally restricted by sonority where it is categorically realized after vowels, variably realized after the liquid consonants, and in contemporary Picard, not realized after nasals or obstruents. Examples are found in (10).

(10) Picard Subjunctive Morpheme Distribution
a. [ki.fi.nif] 'that he finish subj.3sg'
b. [ki.mœr]] 'that he die subj.3sg'
c. [ki.bryl] 'that he burn subj.3sg'
d. [ki.lo.t $\left.\int y p\right]$ 'that he occupy subj.3sg'

Despite the high sonority of /r/, only 5 verbs are listen in Calais's Art de Conjuguer as taking the subjunctive morpheme. However, speaker-elicited data show that many more verbs do overtly mark the subjunctive for some speakers. The subjunctive is realized less often after $/ 1 /$ in speaker-elicited data and is even rarer in grammars. The distribution of this morpheme raises three questions about liquids. Firstly, if $/ \mathrm{r} /$ and $/ 1 /$ have the same, or similar sonority, why is the morpheme's realization more restricted after /1/? Secondly, does a difference in sonority between these two consonants (Côté, 2000) adequately account for this difference? Finally, does a difference in place feature as proposed for onsets in section 2 help to explain the distribution of liquid consonants in codas?

The role of sonority is clearly apparent in the relative distribution of these consonants together in that pérle [perl] 'speaks' is possible but the *pérle [pelr] is not. This example supports a difference in sonority, where the rhotic is more sonorous than the lateral as codas generally prohibit rising sonority. It is now important to examine the role this difference in sonority interacts with the distribution of the subjunctive morpheme or if the distribution must reference the place feature difference as well. Tableau (3) shows the subjunctive morpheme realized after $/ \mathrm{r} /$. The relevant new constraints are presented in (11).

(11) Constraints: Rhotic-Final Subjunctive

REALIZE-MORPHEME: Morphemes in the Input have correspondents in the Output (Kurisu, 2001; van Oostendorp, 2005)

CODA-Son ${ }^{4}$ : Consonants closest to the nucleus have high sonority. Therefore $* l_{2}>>* r_{2}$ where subscript 2 indicates the innermost consonant of a cluster (Baertsch, 2002)

Tableau (3): qu'i meurche

\begin{tabular}{|c|c|c|c|c|c|}
\hline$/ \mathrm{mœr}+\mathrm{f} /$ & WD-CONT & REALIZE & $*_{r_{2}}$ & MAX-C & $\operatorname{DEP}(\mathrm{e})$ \\
\hline ra. [mœr $]$ & & & ** & & \\
\hline b. [mœr] & & $* !$ & & $*$ & \\
\hline c. [mœ.ref] & $* !$ & & & & $*$ \\
\hline $\begin{array}{ll}\text { d. } & {[\mathrm{m} œ]}\end{array}$ & $* !$ & & & $*$ & \\
\hline
\end{tabular}

Candidate (b) is eliminated because the subjunctive morpheme is not realized in the output. Candidates (c) and (d) violate the WD-CONT constraint by inserting an epenthetic segment and deleting a segment wordinternally, respectively. Candidate (a) violates the constraint on sonority, though not fatally. Continuing with an analysis based solely on sonority, tableau (4) examines the same phenomena in a lateral-final stem.

Tableau (4): qu’i brûle

\begin{tabular}{|c|c|c|c|c|c|}
\hline /bryl+s/ & WD-CONT & $* l_{2}$ & REALIZE & MAX-C & $\operatorname{DEP}(\mathrm{e})$ \\
\hline [bryl] & & & $*$ & $*$ & \\
\hline b. [brylf] & & $* !$ & & & \\
\hline c. [bry.le $]$ & $* !$ & & & & $*$ \\
\hline d. $[$ bry $]$ & $* !$ & & & $*$ & \\
\hline
\end{tabular}

\footnotetext{
${ }^{4}$ This crucially assumes a difference in sonority between the lateral and rhotic consonants as in Côté (2000)
} 
The outcomes of tableau (4) are similar to those seen in tableau (3) with the exception that the $* l_{2}$ constraint is ranked more highly than the REALIZE constraint, thus accounting for the more common output without the subjunctive morpheme in lateral-final stems.

Tableaux (3) and (4) do suggest that the subjunctive morpheme is realized less often after a lateral than a rhotic, which is what the data show. While a sonority-based analysis seems adequate in order to account for the facts examined so far, example (12) shows that sonority alone fails to predict the absence of $/ \Varangle /$ in the subjunctive form of travailler.

\section{(12) Glide-Final Stems \\ qu'i travaille [ki.tra.vaj] 'that he work subj.pres.3sg'}

Given that the CODA-SON constraint is formalized as $* l_{2}>*_{r_{2}}>*_{j_{2}}$, sonority predicts that the morpheme will be realized more often after $/ \mathbf{j} /$ than after rhotic-final stems. However, data drawn from Calais' Art de conjuguer and my own corpus reveal the opposite situation. This leads to the proposal of a constraint against two adjacent [coronal] segments as both $/ \mathrm{j} /$ and $/ \mathrm{J} /$ have this place specification in common. Tableau (5) gives the analysis that accounts for the unrealized subjunctive morpheme in this environment and (13) provides the relevant new constraint.

(13) Constraint: Glide-Final Stem

OCP-CODA [CORONAL]: Avoid sequences of consonants in the coda that share the place feature [coronal]

Tableau (5): qu'i travaille

\begin{tabular}{|c|c|c|c|c|c|}
\hline /tra.vaj+s/ & WD-CONT & $\begin{array}{l}\text { OCP-CODA } \\
\text { [CORONAL] }\end{array}$ & REALIZE & MAX-C & $\operatorname{DEP}(\mathrm{e})$ \\
\hline [tra.vaj] & & & $*$ & & \\
\hline b. [tra.vajf] & & $* !$ & & & \\
\hline c. [tra.va.jes] & *! & & & & $*$ \\
\hline d. [tra.vaf] & $* !$ & & & $*$ & \\
\hline
\end{tabular}

Candidate (b) is eliminated due to the OCP-CODA [CORONAL] constraint. Candidates (c) and (d) are eliminated due to the WD-CONT constraint. Since both of these constraints are more highly ranked than the REALIZE constraint, candidate (a) surfaces as the optimal candidate by not realizing the subjunctive morpheme. In tableau (6), the same result is achieved for lateral-final stems with the new constraint.

Tableau (6): qu'i brûle

\begin{tabular}{|c|c|c|c|c|c|c|}
\hline /bryl $+\int /$ & WD-CONT & $\begin{array}{c}\text { OCP- } \\
\text { CODA } \\
{[\text { CORONAL] }}\end{array}$ & $* l_{2}$ & REALIZE & MAX-C & DEP(e) \\
\hline [bryl] & & & & $*$ & $*$ & \\
\hline b. [brylf] & & $* !$ & $*$ & & & \\
\hline c. [bry.le $]$ & $* !$ & & & & & * \\
\hline d. $\left[\right.$ bry $\left.\int\right]$ & $* !$ & & & & $*$ & \\
\hline
\end{tabular}

The addition of this constraint does not predict the absence of $\left[\int\right]$ after the lateral any better than the analysis based on sonority. It is only because of $/ j$ / final examples that the necessity of the OCP-CODA [CORONAL] constraint becomes clear. One complication of this analysis is the presence of sequences of [coronal] consonants as in $i$ consulte [sylt] 'he consults' and $i$ otchup' $t$ [t $\int \mathrm{ypt}$. In order to account for this, the OCP [CORONAL] constraint which already has more stringent onset and coda correlates in this paper, can again be specified to account for the difference between underlying and derived environments. Auger (2000) and Hendrickson \& Auger (2010) propose that final voiceless stops are possible appendices in Picard, accounting for the possibility of complex sequences of consonants with the same sonority. Therefore, a version of the OCP [CORONAL] constraint, OCP-APPENDIX [CORONAL], which is ranked more lowly than the constraint, would account for these cases. With this taken under consideration, the final constraint ranking for codas is proposed in (14). 
(14) Constraint Ranking for Codas

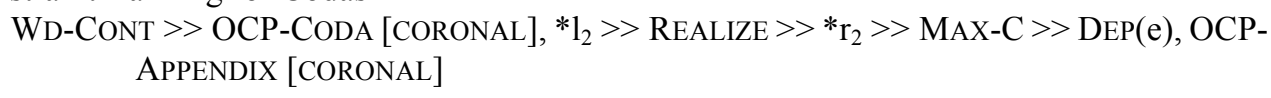

The ranking of constraints in this section has the advantage of showing that a complex interaction between sonority and place features drives the distribution of the subjunctive morpheme. Furthermore, it relates phenomena in onset and coda positions. Section 5 presents conclusions as well as areas for further research.

\section{Conclusions and Areas for Further Study}

The distribution of the liquid consonants both in complex onsets and codas provides evidence that the place feature [coronal] plays an important role in the phonotactics of the liquid consonants both onsets and in codas in Picard. By specifying the lateral as [coronal] at the phonological level, this analysis explains the more restricted distribution of the consonant around other [coronal] consonants. The underspecification of the rhotic consonant at the phonological level allows it to surface faithfully more often, despite its phonetically coronal realization.

This paper adds support for this distinction by looking at liquid-glide onsets and complex codas in Picard. The place specification causes variable deletion of the lateral due to the OCP-ONS [CORONAL] constraint, where the rhotic (and cases where the lateral does not delete) are realized through resyllabification or vowel epenthesis. While sonority plays a major role in the realization of the subjunctive morpheme $/ \mathrm{S} /$ in complex codas, the place specification for the lateral supports a more nuanced distribution due to the OCP-CODA [CORONAL] constraint that also accounts for its distribution after $/ \mathrm{j} /$.

Picard also exhibits cases of word-internal metathesis that functions mainly on rhotic consonants another area that merits further study. Rhotics in complex onsets undergo metathesis with the nucleus in order to be realized in the coda. For example, the word for 'ant' French is fourmi [fuRmi]. In Picard, the first syllable shows metathesis: [fru.mi]. I plan to look at this phenomenon through the feature [coronal], or lack thereof in the rhotic consonant, in order to examine why this same process does not occur in the lateral. If such an analysis adequately accounts for the observed metathesis, it will align with the theory of perceptual metathesis from Blevins and Garrett (1998) where consonants with less structure are more likely to undergo metathesis.

This work helps us look at part of a complicated issue in phonology - the representation of the liquid consonants. By looking at onsets, codas, and eventually metathesis, we can obtain support from various environments and through various effects in order to have a clearer picture of their similarities and differences.

\section{References}

Auger, Julie. 2000. Phonology, variation and prosodic structure: Word-final epenthesis in Vimeu Picard. Paper presented to the Proceedings of the First International Conference on Language Variation in Europe (ICLaVE), Barcelona: Universitat Pompeu Fabra, 2000.

Auger, Julie. 2001. Phonological Variation and Optimality Theory: Evidence from Word-Inital Vowel Epenthesis in Picard. Language Variation and Change 13.253-303.

Auger, Julie. 2003. The development of a literary standard: The case of Picard in Vimeu-Ponthieu, France. When Languages Collide, ed. by B.D.J.e. al. 141-64. Columbus: Ohio State University Press.

BAertsch, Karen. 2002. An Optimality Theoretic Approach to Syllable Structure: The Split Margin Hierarchy. Indiana University, Bloomington, Indiana.

Blevins, Juliette \& ANDREw GarRetT. 1998. The Origins of Consonant-Vowel Metathesis. Language 74.508-56.

CATFORD, JoHn C. 1977. Fundamental problems in phonetics Bloomington: Indiana University Press.

ChÉs DiseuX GROUP. 2012. Chés Diseux. http://ches.diseux.free.fr/

Clements, G.N. 1990. The role of the sonority cycle in core syllabification. Papers in Laboratory Phonology I: Between the 
Grammar and Physics of Speech, ed. by J.K.M. Beckman, 283-333. Cambridge: Cambridge University Press.

Colantoni, Laura and Jeffrey Steele. 2005. Liquid Asymmetries in French and Spanish. Toronto Working Papers in Linguistics 24.1-14.

CôTÉ, MARIE-HÉLĖNE. 2000. Consonant cluster phonotactics: A perception-based approach. MIT Linguistics Dissertations. Cambridge: MIT Working Papers in Linguistics, 367 pp

CôTÉ, MARIE-HÉLÈnE. 2004. Syntagmatic distinctions in consonant deletion. Phonology 21.1-41.

Dickey, LaURA WALSH. 1997. The Phonology of Liquids. Massachusetts: University of Massachusetts Amherst.

Dresher, B. Elan. 2009. The Contrastive Hierarchy in Phonology. Cambridge: Cambridge University Press.

Hendrickson, Ryan \& Julie Auger. 2011. Picard Verbal Morphology: What It Tells Us about Syllable Structure. Paper presented at the CUNY Conference on the Phonology of Endangered Languages, New York, NY.

JefF MielKe. Emergent Feature Theory. 2008. In Edwards, Midtlyng, Sprague, and Stensrud, eds., CLS 41: The Panels. Proceedings from the Panels of the 41st Meeting of the Chicago Linguistic Society. Volume 41-2. Chicago: CLS. 259-273.

Kenstowicz, Michael. 1994. Phonology in Generative Grammar Massachusetts: Blackwell Publishing.

Kurisu, Kazutaka. 2001. The Phonology of Morpheme Realization. PhD thesis, University of California at Santa Cruz. Available as ROA 490-0102.

McDougall, Kirsty \& Mark Jones. 2011. Liquid Polarisation in Australian English. Paper presented at the ICPhS XVII, Hong Kong.

MielKe, JefF. 2005. Ambivalence and Ambiguity in Laterals and Nasals. Phonology 22.169-203.

Paradis, Carole et Jean-François Prunet. 1991. The Special Status of Coronals: Internal and External Evidence, Phonetics and Phonology vol. 2, Academic Press, San Diego, 232 p.

Proctor, Michael. 2011. Towards a gestural characterization of liquids: Evidence from Spanish and Russian. Laboratory Phonology 17.451-85.

VAN DER TORRE, ERIK JAN. 2003. Dutch sonorants - the role of place of articulation in Dutch phonotactics. Leiden University.

VAN OOSTENDORP, MARC. 2005. Expressing inflection tonally, Catalan Journal of Linguistics 4(1), 107-127.

VASSEUR, GASTON. 1996. Grammaire des parlers picards du Vimeu (Somme) Abbeville: F. Paillart.

VAsseur, Gaston. 1998. Dictionnaire des parlers picards du Vimeu (Somme): Avec considération spéciale du dialecte de Nibas Fontenay-sous-Bois: Sides. 